\title{
Critical Evaluation of Melaleuca alternifolia: A Review of the Phytochemical Profile, Pharmacological Attributes and Medicinal Properties in the Botanical, Human and Global Perspectives
}

\author{
Ibrahim Kasujja (1) \\ School of Human Nutrition, McGill University, Montreal, Canada \\ Email: Ibrahim.kasujja@mail.mcgill.ca
}

How to cite this paper: Kasujja, I. (2021) Critical Evaluation of Melaleuca alternifolia: A Review of the Phytochemical Profile, Pharmacological Attributes and Medicinal Properties in the Botanical, Human and Global Perspectives. Open Journal of Medicinal Chemistry, 11, 1-15.

https://doi.org/10.4236/ojmc.2021.111001

Received: December 14, 2020

Accepted: March 28, 2021

Published: March 31, 2021

Copyright $\odot 2021$ by author(s) and Scientific Research Publishing Inc. This work is licensed under the Creative Commons Attribution International License (CC BY 4.0).

http://creativecommons.org/licenses/by/4.0/

\begin{abstract}
Melaleuca (tea tree) oil has become increasingly commonly used in recent decades. The essential oil in Australia for the past 120 years is now available globally as an active component in various products. Historically, Melaleuca oil is known for its antiseptic and anti-inflammatory actions. Currently, microwave technology is applied to extract Melaleuca oil, but this extraction technology is not commercially under practice. Traditionally, Melaleuca oil extraction is possible through steam distillation of the Melaleuca alternifolia terminal branches and leaves, and the resultant extract is always either clear or pale yellowish. Melaleuca oil has been promoted as a therapeutic agent because scientific studies indicate that the Rideal-Walker (RW) coefficients of its extract composition include 8 for cymene, 16 for terpineol, 13.5 for tepinen-4-ol and 3.5 for cineole. The mode of action against bacteria is now partially elucidated, and assumptions exist. Hydrocarbons partition into biological membranes to disrupt the vital functions of Melaleuca oil, and also its components behave in the same manner. Therefore, the inhibition of respiration and the leakage of ions or loss of intracellular material and the inability to maintain homeostasis reflect the loss of membrane integrity and lysis in Melaleuca oil products containing lower than usual terpenes concentrations. Melaleuca oil possesses antifungal properties and is known exclusively for the treatment of Candida albicans. This essential oil strongly changes the permeability of Candida albican cells. C. albicans treatment with $0.25 \%$ tea tree oil leads to propidium iodide uptake. However, a significant loss of $260-\mathrm{nm}$ light-absorbing materials after staining with methylene blue occurs after 6 hours. Melaleuca extracts alter the permeability of Candida glabrata that oc-
\end{abstract}


curs when the membrane is treated with $0.25 \%$ Melaleuca oil. Melaleuca oils possess antiviral properties but most findings evidence that this oil fights against both non-enveloped and enveloped viruses, although the range of viruses tested to date is minimal. Melaleuca oil is known for its antiprotozoal activity because it causes a 50\% reduction in the growth of protozoa Leishmania major and Trypanosoma brucei at concentrations of $403 \mathrm{mg} / \mathrm{ml}$ and $0.5 \mathrm{mg} / \mathrm{ml}$, respectively, based on the studies done (in comparison to controls). An investigation has shown that terpinen-4-ol also contributes significantly to antiprotozoal activity. Tea tree oils at $300 \mathrm{mg} / \mathrm{ml}$ killed all cells of Trichomonas vaginalis, and also anecdotal in-vivo studies evidence that Melaleuca oil may be effective in treating infections caused by Trichomonas vaginalis. This review article summarizes the developments in our understanding of the phytochemistry, bioactivity, metabolism and the economic aspects of Melaleuca alternifolia, and it details how Melaleuca alternifolia species have evolved in the ecosystem.

\section{Keywords}

Melaleuca alternifolia, Terpenes, Terpenoids, Phytotoxicity, Pharmacokinetics, Melaleuca OR Tea Tree Oil, Phytochemistry, Bioactivity

\section{The Botanical Perspective}

\subsection{Phytochemistry}

The Myrtaceae family consists of Tea tree pants which are native to Oceania and are used in Australian traditional medicine by the Aborigine people, and mainly because of their wide-spectrum antimicrobial action [1]. However, M. linariifolia, M. dissitiflora, and other species of Melaleuca can also be used in traditional medicine [2]. Tea tree oil is an essential oil obtained from M. alternifolia and shows the longest history of medicinal uses [3]. Tea tree oil contains about $80 \%$ $90 \%$ of several monoterpenes (1,8-cineol, limonene, sabinenep-cymene, $\alpha$-terpineol, $\alpha$-pinene, terpinolene, terpinen-4-ol and $\alpha$-terpinene) [4]. Aromatic compounds and Sesquiterpenes also contain this type of oil [1]. Three new compounds, designated as melaleucins A-C (1-3), along with seven known compounds including methyl eugenol, 3,4,5-trimethoxy-benzoic acid methyl ester, 3'methoxymiliumollin, vomifoliol, betulinic acid, $\beta$-sitostenone, and $\beta$-sitosterol have also been identified from $M$. alternifolia and $M$. linariifolia species [5].

Terpinen-4-ol is functionally active on $\mathrm{Na}+$ /glucose co-transporters operating in the ileum to transport glucose into the blood, however, this action can be inhibited by $(+)$-catechin and its derivatives in teas [6]. 1,8-Cineole has anti-inflammatory properties, and it reduces the neural excitability [2]. Together with other terpenoids, 1,8-Cineole functions as an antinociceptive agent and has myorelaxant actions in guinea-pig airways and these actions may be induced in humans as well [3]. This review presents commonly recognized phytocomponents abundant in Melaleuca alterifolia (Figure 1). 
(a)<smiles>CC(O)[GeH]C1=CCC(O)(C(C)C)CC1</smiles>

(d)<smiles>C=C(C)CCC(C)C</smiles>

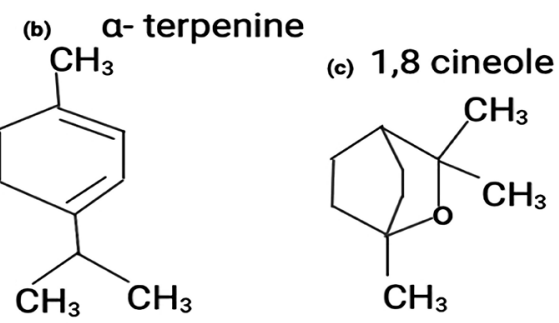

$\mathrm{H}_{3} \mathrm{C}$

Figure 1. Chemical structures of key Melaleuca phytocomponents.

\subsection{Bioactivity}

Melaleuca alternifolia and the other species of Melaleuca have been extensively studied and investigated for their broad-spectrum antimicrobial activity [4]. Also 1,8-cineol, terpinen-4-ol and methyl eugenol are vital in mediating tea tree oil antimicrobial activity [7]. Besides Tea tree oil's effectiveness in fighting antibacterial infections, the oil also has antifungal properties [6]. Antifungal mechanisms of $\alpha$-terpineol and terpene-4-alcohol are crucial in the use of $M$. alternifolia in Austrian traditional medicine [1]. In 2014, it was discovered that M. alternifolia can treat dermatological disorders, and has a safe profile in tropical medicine [7]. A variety of tea-tree plant polymorphs and chemotypes such as terpene chemotypes are known to protect $M$. alternifolia against two specialist leaf beetles and susceptibility to Myrtle Rust [8].

Tea tree exhibits a wide spectrum of antimicrobial activities with a minimal inhibitory concentration of $2.06 \mathrm{mg} / \mathrm{ml}$, on average [9]. The modes of action against Gram-positive bacterium Staphylococcus aureus (0.12 to $1 \mathrm{mg} / \mathrm{ml})$, Gram-negative bacterium Escherichia coli $(0.12$ to $1.5 \mathrm{mg} / \mathrm{ml})$, Aspergillus fumigatus (1.78 $\mathrm{mg} / \mathrm{ml}$ ) and yeast, Candida albicans $(0.05$ to $0.5 \mathrm{mg} / \mathrm{ml}$ ) have been investigated, but clearer evidence requires conducting more research [10]. M. alternifolia oil is a supplementary therapy in pythiosis treatment, but further studies are needed to appraise the applicability of the prescription of the plant's essential oil in clinical pythiosis [11]. The antimicrobial activity of $M$. alternifolia has been widely studied against different microorganisms, including parasites, viruses, bacteria and in true fungi [12]. Essential oils of aromatic plants have been used in the alternative treatment of different diseases, and oils have demonstrated low toxicity to mammalian cells and minor environmental impact and good acceptance by consumers [13]. An important aquatic oomycete (Pythium insidiosum) which causes pythiosis in both animals and humans can be prevented using M. alternifolia essential oil [13]. Pythium insidiosum shows low susceptibility to the available antifungal drugs as well [11]. Though there are six different chemotypes of terpenes, this review emphasizes chemotypes 1 and 2 terpenes (Figure 2). 


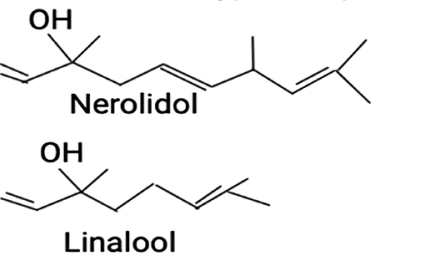

(b)

Chemotype 2 terpenes

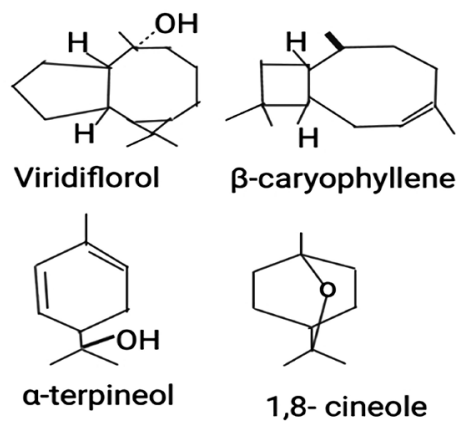

Figure 2. Chemotype structures for terpenes.

Further research is required for antimicrobial activity of Melaleuca alternifolia in its free oil, and nanoemulsion formulations against Brazilian P. insidiosum isolates [14]. Tea tree essential oil is effective at controlling native microflora growth and counteract exogenous Escherichia coli O157:H7 contamination in the preharvest application of chitosan and butterhead lettuce [15]. Tea tree essential oil is a bio preservative that controls native microflora growth in butterhead lettuce plants during the postharvest refrigerated storage; possibly counteract $E$. coli $\mathrm{O} 157: \mathrm{H} 7$ contamination during the inadequate postharvest management of the leafy vegetable by assessing the survival and growth of the pathogen [15].

\subsection{Evolution}

Melaleuca alternifolia (Maiden and Betche) Cheel, or tea tree, is the principal source plant for the Australian tea tree oil industry [16]. With a scattered regional distribution, tea trees are restricted to sandy soils over granite, along the creeks and rivers of northeastern New South Wales (NSW) and southeastern Queensland, Australia [17]. The evolution of Tea tree phytochemicals and polymorphs is due to both interpopulation and intrapopulation variations [1]. The tree is a medium-sized tree with a papery bark [7]. Medicinal tea tree (Melaleuca alternifolia, Myrtaceae) is a small tree from mostly low-lying swamps in a restricted area of north-east NSW and south-east QLD, Australia [18] that produces economically valuable foliar essential oil. The leaves have numerous oil glands and the white, terminally borne flowers are morphologically bisexual and insect-pollinated [16]. Existing tea tree plantations have predominantly been established from a limited genetic pool of extant wild selections that do not represent the full potential of the species and could, in the long term, expose the industry to pest and disease outbreaks [19]. The chemical variation has always been intriguing, and points towards an adaptive role of plant chemical diversity, and intraspecific chemical variation can contribute to an understanding of the evolution of genus Melaleuca [20]. Besides traditional medicinal use of tea tree plants, and efficient tree-breeding strategy is required to improve the final product and maintain the competitiveness of the industry [21]. The main factor contributing to the difference in allelic frequency and distribution is the lack of 
gene flow between the states owing to the presence of geographical barriers in the form of mountain ranges and clearing for agricultural purposes [16]. There is limited evidence to support the evolution of Melaleuca. alternifolia, from other less known species of the genus Melaleuca [18].

\subsection{Ecosystem}

A variety of wild relatives of cultivated tea plants are basically distributed in the Yangtze River Basin and its southern reaches, particularly in Yunnan, Guizhou, and Guangxi provinces [22]. Generally, the antimicrobial activity and bioactive components of tea tree essential oil are based on its components [6]. Besides, the composition of tea tree plant oil is highly variable according to different geographic, environmental, and ecological and coastal conditions [21]. Historical literature reveals that the cultivation centre of Melaleuca migrated from west to east and then to south, which is supported by huge changes in genetic diversity [22]. Melaleuca oil and its constituents have lipophilic properties and small molecular weights and can ably cross cell membranes altering the phospholipid bilayers, increasing membrane fluidity and exacerbating leakage of ions and cytoplasmic content [6]. The primary constituents of the tea tree plant oil, for example; 1,8-cineol, terpinen-4-ol, and terpinolene should be in an optimal balance [20]. An optimal balance between Terpinen-4-ol and 1,8 cineol is being considered essential for both antimicrobial and skin absorption properties [20]. Tea tree oil is found in some household products, including cleaning products and It is promoted as being "natural" and "better for the environment" [6]. Being "natural" does not necessarily mean "non-toxic" or "non-poisonous"; tea tree oil is irritating to some people and is poisonous to swallow [8]. M. alternifolia products should be used according to label instructions and stored safely in their original containers, out of reach of children, and apart from medicines and food [23].

\section{The Human Perpective}

\subsection{Pharmacognosy}

The uses of tea tree oil and the tea tree plant have not all been tested for safety or effectiveness [24]. The skin problems occur most prominently in traditional uses of tea tree oil and include bruises, burns, canker sores, eczema, psoriasis, rosacea, and skin infections [24]. Besides that, several respiratory conditions are noted and these include colds, cough, bronchial congestion, and nose and throat irritation [23]. Frequent use of $M$. alternifolia products can lead to a variety of conditions which include melanoma, body odour, and infections of the bone and prostate [23]. M. alternifolia essential oil can cause dangerous poisoning in less than thirty minutes [24].

\subsection{Pharmacodynamics}

Approximately $20 \%$ of Melaleuca oil solution contains huge concentrations of 
cineole, a skin irritant that reduces the antiseptic properties of terpinen-4-ol (purported active ingredient) [25]. Besides, terpinen-4-ol, 2\% - 4\% tea tree oil concentrations contain other active ingredients such as 1,8-cineole, alpha-terpineol, and gamma-terpinen [6]. These bioactive components are responsible for the anti-cancer, anti-fungal, anti-inflammatory and dental effects in humans [26]. Tea tree oil, however, reacts preferentially with the less ordered DPPC "sea" and does not modify the more ordered lipid "rafts." [27]. Tea tree oil interacts with multi-drug resistant (MDR) melanoma cell plasma membrane and interferes with the function of the MDR drug transporter P-gp [26]. The effect imposed on MDR melanoma cells is preferably mediated by the interaction with the fluid DPPC phase, rather than with the more organized "rafts", and this interaction preferentially affects the ATP non-dependent antiapoptotic action of P-gp likely localized outside "rafts" [25]. Periodontopathic bacterial strains that are tested, including but not limited to Porphyromonas gingivalis, Actinobacillus actinomycetemcomitans, Streptococcus mutans, and Streptococcus sobrinus, were maximally destroyed by 30s of exposure to Melaleuca oil and has shown significant adhesion-inhibiting action against $\mathrm{P}$. gingivalis [28]. Tea tree oil suppresses the production of tumour necrosis factor-alpha, interleukin- $1 \beta$, interleukin-10, and prostaglandin E2 by activated monocytes in vitro, induces differentiation of myelocytes into monocytes, and suppresses the production of superoxide by activated monocytes in vitro [29]. Tea tree oil is active against Madurella mycetomatis, and Trichophyton mentagrophytes; and tea tree oil is known to fight against certain fungi that are resistant to both fluconazole and itraconazole [30]. Dandruff is most times related to yeast, Pityrosporum ovale, and 5\% concentrations of Tea tree oil shampoos have antifungal properties against $\mathrm{P}$. ovale [31].

\subsection{Pharmacokinetics}

\subsubsection{Absorption}

Tea tree oil products applied to the human skin affect skin integrity and the percutaneous penetration of benzoic acid dose-dependently [14] [32]. Minute amounts of tea tree oil components, $1.5 \%$ and $3 \%$ of the applied quantities following application of a $20 \%$ concentrated tea tree oil solution and pure tea tree oil, respectively, penetrate into or through the human epidermis layer [32] [33]. Terpinen-4-ol is the largest tea tree oil component that penetrates the skin, and following the partial occlusion of the application site, the penetration of terpinen-4-ol increased to approximately $7 \%$ of the applied tea tree oil [33]. The measurement of the evaporation rate of Tea tree oil from filter paper $\left(7.4 \mathrm{mg} / \mathrm{cm}^{2}\right)$ shows that approximately $98 \%$ of the oil evaporates within the first four hours [34]. 1\% tea tree oil does not affect the barrier conditions in an experimental in vitro model using static diffusion cells with human skin [32] [33]. The flux values are reduced remarkably due to the lower amount of terpinen-4-ol. P(app) values for cream $\left(2.74 \pm 0.06 \times 10^{-7} \mathrm{~cm} / \mathrm{s}\right)$, and native tea tree oil $(1.62 \pm 0.12 \times$ $\left.10^{-7} \mathrm{~cm} / \mathrm{s}\right)$ are therefore comparable, even though white petrolatum $(6.36 \pm 0.21$ 
$\left.\times 10^{-7} \mathrm{~cm} / \mathrm{s}\right)$ and semisolid $\mathrm{O} / \mathrm{W}$ emulsion $\left(8.41 \pm 0.15 \times 10^{-7} \mathrm{~cm} / \mathrm{s}\right)$ have exceedingly greater values indicating a penetration enhancement [35].

\subsubsection{Distribution}

Terpinen-4-ol, methyl eugenol, 3'methoxymiliumollin, vomifoliol, betulinic acid, $\beta$-sitostenone, and $\beta$-sitosterol are distributed to the human liver for metabolism, within a couple of hours after application of Tea tree oil creams [36].

\subsubsection{Metabolism}

The microsomes contain CYP2A6, a principal enzyme involved in the oxidation of (-)-terpinen-4-ol in the human liver [37]. Based on existing evidence, CYP2A6 has the highest activity for oxidation of (-)-terpinen-4-ol, and oxidation of (-)terpinen-4-ol is inhibited by (+)-menthofuran [38]. The oxidative and hydrolytic stability of $\alpha$-Terpinene is illustrated (Figure 3 ).

There are no reports on the biotransformation of (-)-terpinen-4-ol by human liver microsomes [39]. The previous studies have demonstrated that several monoterpenoids, including 1,4-cineole, and 1,8-cineole, (+)-, but also (-)-limonenes, and (-)-menthols are metabolized by cytochrome P450 enzymes in human liver microsomes [38] [39]. A simple illustration of the metabolic pathway to 1,8 cineole is presented (Figure 4). Enzymes efficiencies (Vmax/Km ratio) were $\sim 3$-fold higher for the formation of (-)-(1S,2R,4R)-1,2-epoxy-menthan-4-ol than for (-)-(1R,2S,4R)-1,2-epoxy-pmenthan-4-ol [39].

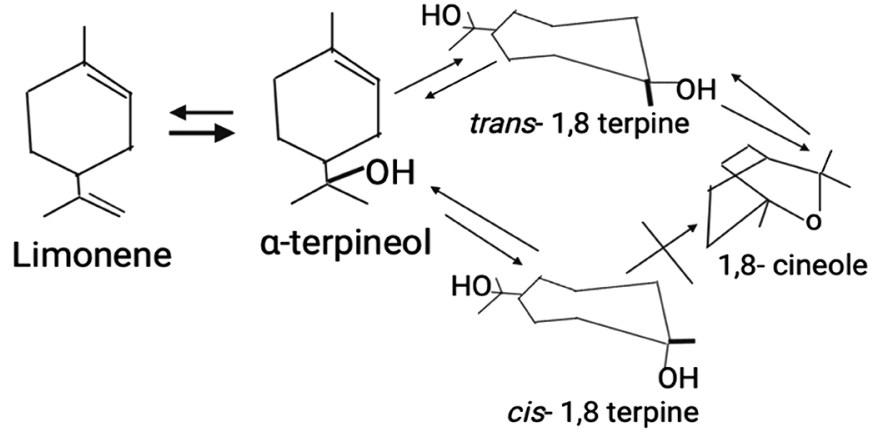

Figure 3. Metabolic pathway for Limonene, alpha-terpineol and 1,8 cineole.

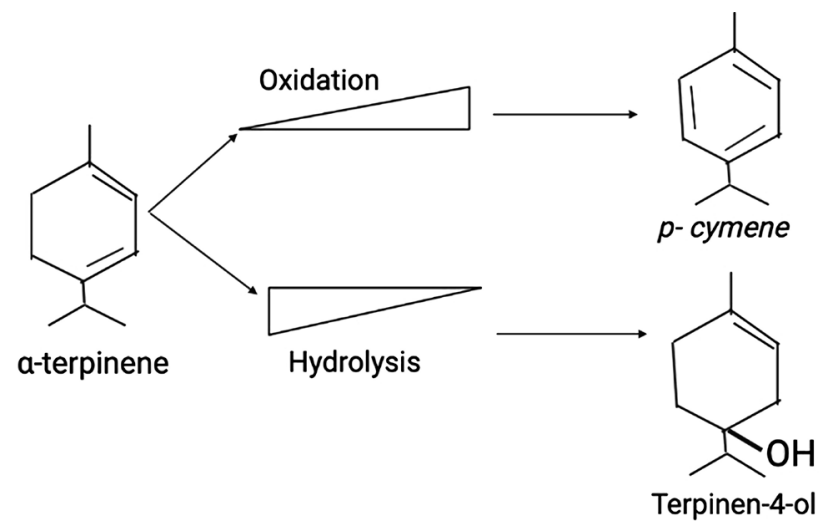

Figure 4. Alpha-terpinene hydrolysis and oxidation. 


\subsubsection{Excretion}

Like most phytochemicals from other plants, terpinen-4-ol, methyl eugenol, 3'methoxymiliumollin, vomifoliol, betulinic acid, $\beta$-sitostenone, and $\beta$-sitosterol and are excreted highly in urine as metabolites that are formed in host tissues or by the microbiota and constitute a high proportion of the urinary metabolome [40].

\subsection{Phytotoxicity}

Little is known of the toxicity of the individual components or the whole tea tree essential oil [23] [41]. Although there is no confirmation, Melaleuca essential oil must not be ingested in relatively high amounts due to its toxicity, even though no fatal cases have been reported in the medical literature [18] [42]. Tea tree oil poisoning can cause muscle tremors, weakness, difficulty walking, low body temperature, and excessive salivation [20]. At present, the Australian standard (AS 2782-1985) is regulating the levels of two components which stipulates that terpinen-4-ol, the putative antimicrobial compound, must be comprised at least in $30 \%$ of the Melaleuca oil, while 1,8-cineole, reputedly a skin irritant, must not exceed $15 \%$ in Tea tree products [43]. While the antimicrobial activity of terpinen-4-ol has been justified, the role of 1,8-cineole is less clear [16] [43]. The lipophilic (lipid loving) character of tea tree oil and its ability to penetrate epidermis may incredibly potentiate its toxicity [14] [44]. Given the widespread availability of an extensive range of tea tree oil products, the paucity of accurate toxicity data represents a serious problem [6] [45]. There is limited evidence to support the fact that tea tree oil improves immunity, however, research suggests that the effect of tea tree oil on hepatic and renal functions and the immune response of rats infected by Trypanosoma evansi is significant, and this can apply to humans [41] [46]. Therefore, it is possible to conclude that tea tree oil influences the levels of inflammatory mediators and has the trypanocidal effect, increasing life expectancy of rats infected by T. evansi [42] [44]. The human body may not necessarily detoxify tea tree oil, available in over-the-counter skin products, including soaps and lotions [44] [47]. However, tea tree oil should not be consumed orally and If swallowed, it can cause serious symptoms especially in higher concentrations [23] [48]. Tea tree oil is known to be dangerous, and even poisonous if swallowed, and a child who swallowed only a smaller quantity given to him by mistake went into a coma (from which he recovered later on) [17] [49]. Tea tree oil should NOT be taken orally for any reasons, even though some traditional uses include tea tree oil as a mouthwash, treatment for bad breath, and treatment of toothache and mouth ulcers [45] [50].

\section{The Global Perspective}

\subsection{Domestication}

Although China and India are the two largest tea-producing countries, $M$. alternifolia's origin and breeding history in these two countries remain unclear [46]. 
Wild tea trees are valuable genetic resources for studying domestication and breeding on the northeast coast of New South Wales, Australia [22] [51]. The not readily noticeable differentiation between primaeval tea trees and cultivars at both genetic and metabolomic levels implies that tea trees may not have undergone long-term artificial directional selection in terms of flavour-related metabolites [52]. Demographic modelling suggests that Melaleuca alternifolia existed in Australia, and Queensland for several decades before being cultivated in Asia [48] [53]. Cultivating tea trees require a suitable climate with a minimum annual rainfall of 1140 to 1270 millimetres, and with proper distribution [46] [54]. If there is a wet and cool season, with average temperatures $\left(11^{\circ} \mathrm{C}\right)$ or more below those of the warmer climate, the growth rate will decelerate and a dormant period will proceed, even when the cool season is the wetter one [15] [55]. Tea tree soils must be relatively acidic; tea trees cannot be grown in alkaline soils [46] [56]. There are no structural differences between domesticated and wild Melaleuca alternifolia, however, the hybrids are of high vigour [22].

\subsection{Socioeconomic}

Tea trees are cultivated, and produce an essential oil (melaleuca oil), with a fresh camphoraceous odour and a colour that ranges from pale yellow to nearly colourless and clear [44] [54]. The oil is derived from the leaves of Melaleuca alternifolia and nothing much is known about the economic impact of $M$. alternifolia oil fraud on the farmers and consumers [51]. The oil comprises many constituent chemicals and its composition changes if it is exposed to air (oxygen), and oxidization results in significant losses on market [50] [55]. The commercial use of tea tree oil began in the 1920s and was pioneered by the entrepreneur Arthur Penfold [51]. The global tea tree oil market was valued at US\$39 million in 2017 [52]. The 2011 National Center for Complementary and Integrative Health (NCCIH) and the 2016 United States National Institutes of Health reports affirm that the tea tree oil is a traditional herbal medicine used to treat acne, nail fungus, or athlete's foot, and tea tree oil is Ubiquitous in the pharmaceutical industry [53]. There is little evidence to support the uses of tea tree oil in modern medicine, and the 2015 Cochrane systematic review for acne complementary therapies, found that a low-quality single dosage showed benefit compared to a placebo [52]. The problems faced by tea tree growers during cultivation, transportation and marketing have not been documented.

\subsection{Environmental}

Tea tree plantations, not only result in the direct loss of habitat but can impact the wider environment. Land clearance alters the natural flow of water and increases soil erosion leading to the loss of wetland habitats and the pollution of rivers and lakes [53]. The application of weedicides, pesticides, and inorganic fertilizers creates environmental hazards, and the process of extracting the essential oil might lead to environmental pollution [47]. The information related to land use and the effects of Melaleuca on local fauna has not been documented. 


\section{Conclusion}

Even though the Melaleuca extract exhibits various therapeutic properties, much attention is given to its antimicrobial activity. The scientific evidence to conclude that Melaleuca oils would be used single-handedly in treating human infections is not sufficient and, therefore, inconclusive. However, existing scientific literature suggests that melaleuca extracts are vital as one of the many active ingredients in pharmaceutical products. In vitro data now support the long-held beliefs that Melaleuca has antimicrobial and anti-inflammatory properties, but despite some progress, clinical evidence demonstrates that the efficacy of these therapeutic agents against bacterial, fungal or viral infections is insufficient. The medical profession should consider recommending viable non-antibiotic approaches such as the use of phages, probiotics and phytomedicines in the spirits of reducing antimicrobial resistance (AMR) in humans. These alternative therapies are viewed favourably by the vast majority because patients perceive that they only result in fewer detrimental side effects, and these side effects rarely happen.

\section{Future Prospectives}

There is tremendous progress in our understanding of Melaleuca alternifolia. Many societies across the globe, including communities in Asia, America, Europe and Africa, are now recognising the therapeutic values and economic attributes of Melaleuca alternifolia. The community recognises the importance of using phytomedicines as potential substitutes for antibiotic therapy to decrease antibiotic resistance. However, large randomised clinical trials are now needed than ever before to evidence a place for Melaleuca oils as a topical medicinal agent. The medical profession should embrace these therapies, even though good scientific data is still minimal. The situation and the perception of Melaleuca extracts and their origin and evolution are changing as we approach the post-antibiotic era. Lastly, there is a need to understand the effectiveness of using Melaleuca extracts to reduce anti-fungal resistance as well.

\section{Acknowledgements}

I would like to thank Professor Patrick Owen at the School of Human Nutrition and Dietetics of McGill for his great support in providing informative resources and instructions that have helped me to write this review paper.

\section{Conflicts of Interest}

The author declares that there is no conflict of interest concerning the publication and referencing the contents in this article.

\section{References}

[1] Javad, S.R., Bahare, S., Elena, M.V., et al. (2017) Plants of the Melaleuca Genus as Antimicrobial Agents: From Farm to Pharmacy. Phytotherapy Research, 31, 1475 
1494. https://doi.org/10.1002/ptr.5880

[2] Trombetta, D., Castelli, F. and Sarpietro, M.G. (2005) Mechanisms of Antibacterialaction of Three Monoterpenes. Antimicrobial Agents and Chemotherapy, 49, 24742478. https://doi.org/10.1128/AAC.49.6.2474-2478.2005

[3] Victoria, D.A. (2005) Those Amazing Tea Tree Oils. Karen MacKenzie Australia. http://www.health247.info/healthbites/bookpdfs/teatreebook.pdf

[4] Nazzaro, F., Fratianni, F., Martino, L.D., Coppola, R. and Feo, V.D. (2013) Effect of Essential Oils on Pathogenic Bacteria. Pharmaceuticals, 6, 1451-1474.

https://doi.org/10.3390/ph6121451

[5] Kong, Q., Zhang, L., An, P., Yu, X., Lu, J. and Ren, X. (2018) Antifungal Mechanisms of $\alpha$-Terpineol and Terpene-4-Alcohol as the Critical Components of Melaleuca alternifolia Oil in the Inhibition of Rot Disease Caused by Aspergillus ochraceus in Post Harvest Grapes. Journal of Applied Microbiology, 126, 1161-1174. https://doi.org/10.1111/jam.14193

[6] Sharopov, F. (2015) Phytochemistry and Bioactivities of Selected Plant Species with Volatile Secondary Metabolites. University of Heidelberg, Heidelberg, 130.

[7] Li, C., Lui, H., Zhao, L., Zhang, W., Qiu, S. and Yang, X. (2017) Antibacterial Neolignans from the Leaves of Melaleuca bracteata. Fitoterapia, 120, 171-176. https://doi.org/10.1016/j.fitote.2017.06.015

[8] Carlos, B.S., Carsten, K. and Willian, F. (2015) Effects of Terpene chemotypes of Melaleuca alterifolia on Two Specialist Leaf Bettles and Susceptibility to Myrtle Rust. Journal of Chemical Ecology, 41, 937-947. https://doi.org/10.1007/s10886-015-0628-0

[9] Hammer, K.A., Carson, C.F. and Riley, T.V. (2002) In Vitro Activity of Melaleuca alternifolia (Tea Tree) Oil against Dermatophytes and Other Filamentous Fungi. Journal of Antimicrobial Chemotherapy, 50, 195-199. https://doi.org/10.1093/jac/dkf112

[10] Sagave, L., Gressler, L.T., Flores, F.C., Silva, C.B., Vargas, A.P.C., Lovato, M., Sangioni, L.A., Pötter, L. and Botton, S.A. (2015) Atividade de nanoformulações de Melaleuca alternifolia e terpinen-4-ol em isolados de Rhodococcus equi. Arquivo Brasileiro de Medicina Veterinária e Zootecnia, 67, 221-226. https://doi.org/10.1590/1678-7454

[11] Ebani, V.V., Najar, B., Bertelloni, F., Pistelli, L., Manciata, F. and Nardoni, S. (2018) Chemical Composition and in Vitro Antimicrobial Efficacy of Sixteen Essential Oils against Escherichia coli and Aspergillus fumigatus Isolated from Poultry. Veterinary Sciences, 5, 1-13. https://doi.org/10.3390/vetsci5030062

[12] Kleine, S. and Müller, C. (2011) Intraspecific Plant Chemical Diversity and Its Relation to Herbivory. Oecologia, 166, 175-186.

https://doi.org/10.1007/s00442-010-1827-6

[13] Kursar, T.A., Dexter, K.G., Lokvam, J., Pennington, R.T., Richardson, J.E., Weber, M.G., Murakami, E.T., Drake, C., McGregor, R. and Coley, P.D. (2009) The Evolution of Antiherbivore Defenses and Their Contribution to Species Coexistence in the Tropical Tree Genus Inga. Proceedings of the National Academy of Sciences of the United States of America, 106, 18073-18078. https://doi.org/10.1073/pnas.0904786106

[14] Flores, F.C., Lima, J.A., Ribeiro, R.F., Alves, S.H., Rolim, C.M.B., Beck, R.C.R. and Silva, C.B. (2013) Antifungal Activity of Nanocapsule Suspensions Containing Tea Tree Oil on the Growth of Trichophyton rubrum. Mycopathologia, 175, 281-286. https://doi.org/10.1007/s11046-013-9622-7 
[15] Goñi, M.G., Tomadoni, B., Roura, S.I. and Moreira, M.R. (2014) Effect of PostHarvest Application of Chitosan and Tea Tree Essential Oil on Post Harvest Evolution of Lettuce Native Microflora and Exogenous E. coli 0157:H7. Journal of Food Safety, 34, 353-360. https://doi.org/10.1111/jfs.12135

[16] Rossetto, M., Slade, R.W., Baverstock, R.J. and Lee, L.S. (2003) Microsatelite Variation and Assessment of Genetic Structure in Tea Tree. Molecular Ecology, 8, 633-643. https://doi.org/10.1046/j.1365-294x.1999.00622.x

[17] Pennacchio, M., Kemp, A.S., Taylor, R.P., Wickens, K.M. and Kienow, L. (2005) Interesting Biological Activities from Plants Traditionally Used by Native Australians. Journal of Ethnopharmacology, 96, 597-601. https://doi.org/10.1016/j.jep.2004.10.012

[18] Keszei, A., Hassan, Y. and Foley, W.J. (2010) A Biochemical Interpretation of Terpene chemotypes in Melaleuca alternifolia. Journal of Chemical Ecology, 36, 652-661. https://doi.org/10.1007/s10886-010-9798-y

[19] Butcher, P.A., Matheson, A.C. and Slee, M.U. (1996) Potential for Genetic Improvement of Oil Production in Melaleuca alternifolia and M. Linariifolia. New Forests, 11, 31-51.

[20] Gulluce, M., Sokmen, M., Daferara, D., Ozkan, G., Kartar, H., Pollisou, N.M., Sokmen, A. and Sahin, F. (2003) In Vitro Antibacterial, Antifungal, and Antioxidant Activities of the Essential Oil and Methanol Extracts of Herbal Parts and Callus Cultures of Satureja hortensis L. Journal of Agricultural and Food Chemistry, 51, 3958-3965. https://doi.org/10.1021/jf0340308

[21] Goldstein, D.B., Linares, A.R., Cavalli-Sforza, L.L. and Feldman, M. (1995) Genetic Absolute Dating Based on Microsatellites and the Origin of Modern Humans. Proceedings of the National Academy of Sciences of the USA, 92, 6723-6727. https://doi.org/10.1073/pnas.92.15.6723

[22] Zhang, W.J., Rong, J., Wei, C.L., Gao, L.M. and Chen, J.K. (2018) Domestication Origin and Spread of Cultivated Tea Plants. Biodiversity Science, 26, 357-372. https://doi.org/10.17520/biods.2018006

[23] Jacobs, M.R. and Hornfeldt, C.S. (1994) Melaleuca Oil Poisoning. Journal of Toxicology Clinical Toxicology, 32, 461-464. https://doi.org/10.3109/15563659409011050

[24] Carson, C.F., Mee, B.J. and Riley, T.V. (2002) Mechanism of Action of Melaleuca alternifolia (Tea Tree) oil on Staphylococcus aureus Determined by Time-Kill, Lysis, Leakage, and Salt Tolerance Assays and Electron Microscopy. Antimicrobial Agents Chemotherapy, 46, 1914-1920. https://doi.org/10.1128/AAC.46.6.1914-1920.2002

[25] Giordani, C., Molinari, A., Toccacieli, L., Calcabrini, A., Stringaro, A., Chistolini, P., Arancia, G. and Diociaiuti, M. (2006) Interaction of Tea Tree Oil with Model and Cellular Membranes. Journal of Medicinal Chemistry, 49, 4588. https://doi.org/10.1021/jm060228i

[26] Straede, A., Corran, A., Bundy, J. and Heinisch, J.J. (2007) The Effect of Tea Tree Oil and Antifungal Agents on a Reporter for Yeast Cell Integrity Signalling. Yeast, 4, 321-334. https://doi.org/10.1002/yea.1478

[27] Williamson, E.M., Priestley, C.M. and Burgess, I.F. (2007) An Investigation and Comparison of the Bioactivity of Selected Essential Oils on Human Lice and House Dust Mites. Fitoterapia, 78, 521-525. https://doi.org/10.1016/j.fitote.2007.06.001

[28] Takarada, K., Kimizuka, R., Takahashi, N., Honma, K., Okuda, K. and Kato, T.A. (2004) Comparison of the Antibacterial Efficacies of Essential Oils against Oral Pa- 
thogens. Oral Microbiology and Immunology, 19, 61-64. https://doi.org/10.1046/j.0902-0055.2003.00111.x

[29] Brand, C., Ferrante, A., Prager, R.H., Riley, T.V., Carson, C.F., Finlay-Jones, J.J. and Hart, P.H. (2001) The Water-Soluble Components of the Essential Oil of Melaleuca alternifolia (Tea Tree Oil) Suppress the Production of Superoxide by Human Monocytes, But Not Neutrophils, Activated in Vitro. Inflammation Research, 50, 213 219. https://doi.org/10.1007/s000110050746

[30] Inouye, S., Uchida, K., Nishiyama, Y., Hasumi, Y., Yamaguchi, H. and Abe, S. (2007) Combined Effect of Heat, Essential Oils and Salt on Fungicidal Activity against Trichophyton mentagrophytes in a Foot Bath. Nippon Ishinkin Gakkai Zasshi, 48, 27-36. https://doi.org/10.3314/jimm.48.27

[31] Satchell, A.C., Saurajen, A., Bell, C. and Barnetson, R.S. (2002) Treatment of Dandruff with 5\% Tea Tree Oil Shampoo. Journal of the American Academy of Dermatology, 47, 852-855. https://doi.org/10.1067/mjd.2002.122734

[32] Nielsen, J.B. (2006) Natural Oils affect the Human Skin Integrity and the Percutaneous Penetration of Benzoic Acid Dose-Dependently. Basic \& Clinical Pharmacology \& Toxicology, 98, 575-581. https://doi.org/10.1111/j.1742-7843.2006.pto 388.x

[33] Nielsen, J.B. and Nielsen, F. (2006) Topical Use of Tea Tree Oil Reduces the Dermal Absorption of Benzoic Acid and Methiocarb. Archives of Dermatological Research, 297, 395-402. https://doi.org/10.1007/s00403-005-0627-z

[34] Cross, S.E., Russell, M., Southwell, I. and Roberts, M.S. (2008) Human Skin Penetration of the Major Components of Australian Tea Tree Oil Applied in its Pure Form and as a $20 \%$ Solution in Vitro. European Journal of Pharmaceutics and Biopharmaceutics, 69, 214-222. https://doi.org/10.1016/j.ejpb.2007.10.002

[35] Reichling, J., Landvatter, U., Wagner, H., Kostka, K.H. and Schaefer, U.F. (2006) In Vitro Studies on Release and Human Skin Permeation of Australian Tea Tree Oil (TTO) from Topical Formulations. European Journal of Pharmaceutics and Biopharmaceutics, 64, 222-228. https://doi.org/10.1016/j.ejpb.2006.05.006

[36] Pfannhauser, W., Fenwick, G.R., Khokhar, S.R. and Royal Society of Chemistry (Great Britain) (2001) Biologically-Active Phytochemicals in Food: Analysis, Metabolism, Bioavailability and Function (Ser. Special Publication, no. (269). Royal Society of Chemistry.

[37] Miyazawa, M., Shindo, M. and Shimada, T. (2001) Oxidation of 1,8cineole, the Monoterpene Cyclic Ether Originated from Eucalyptus Polybractea, by Cytochrome P450 3A Enzymes in Rat and Human Liver Microsomes. Drug Metabolism and Disposition, 29, 200-205.

[38] Miyazawa, M., Shindo, M. and Shimada, T. (2001) Roles of Cytochrome P450 3A Enzymes in the 2-Hydroxylation of 1,4-Cineole, a Monoterpene Cyclic Ether, by Rat and Human Liver Microsomes. Xenobiotica, 31, 713-723.

https://doi.org/10.1080/00498250110065595

[39] Abraham, W.R., Stumpf, B. and Kieslich, K. (1986) Microbial Transformations of Terpenoids with 1-p-Menthene Skeleton. Applied Microbiology and Biotechnology, 24, 24-30. https://doi.org/10.1007/BF00266280

[40] Anthony, F., Rafael, L., Alexina, O., Jean-Francois, M., Estelle, P.G., Catherine, L. and Augustin, S. (2008) Metabolomics Provide Insight on the Metabolism of Dietary Phytochemicals in Rats. Journal of Nutrients, 138, 1282-1287. https://doi.org/10.1093/jn/138.7.1282

[41] Keszei, A., Brubaker, C.L. and Foley, W.J. (2008) A Molecular Perspective on Ter- 
pene variation in Australian Myrtaceae. Australian Journal of Botany, 56, 197. https://doi.org/10.1071/BT07146

[42] Baldissera, M.D., Da Silva, A.S., Oliveira, C.B., Santos, R.C., Vaucher, R.A., Raffin, R.P., Gomes, P., Dambros, M.G., Miletti, L.C., Boligon, A.A., Athayde, M.L. and Monteiro, S.G. (2014) Trypanocidal Action of Tea Tree Oil (Melaleuca alternifolia) against Trypanosoma evansi in Vitro and in Vivo Used Mice as Experimental Model. Experimental Parasitology, 141, 21-27. https://doi.org/10.1016/j.exppara.2014.03.007

[43] Carson, C.F., Hammer, K.A. and Riley, T.V. (2006) Melaleuca alternifolia (Tea Tree) Oil: A Review of Antimicrobial and Other Medicinal Properties. Clinical Microbiology Reviews, 19, 50-62. https://doi.org/10.1128/CMR.19.1.50-62.2006

[44] Standards Association of Australia (2011) Essential Oils-Oils of Melaleuca, Terpinen4-1 Type. Standards Australia, Sydney.

[45] Banerjee, B. (1992) Botanical Classification of Tea. In: Wilson, K. and Clifford, N., Eds., Tea: Cultivation and Consumption, Chapman and Hall, London, 25-51. https://doi.org/10.1007/978-94-011-2326-6 2

[46] Chen, L., Zhou, Z.X. and Yang, Y.J. (2007) Genetic Improvement and Breeding of the Tea Plant (Camellia sinensis) in China: From Individual Selection to Hybridization and Molecular Breeding. Euphytica, 154, 239-248. https://doi.org/10.1007/s10681-006-9292-3

[47] Anderson, E.C. and Thompson, E.A. (2002) A Model-Based Method for Identifying Species Hybrids Using Multi-Locus Genetic Data. Genetics, 160, 1217-1229. https://doi.org/10.1093/genetics/160.3.1217

[48] Zhang, W., Zhang, Y., Qiu, H., Guo, Y., Wan, H., Zhang, X., Scossa, F., Alseekh, S., Zhang, Q., Wang, P., Xu, L., Schmidt, M.H., Jia, X., Li, D., Zhu, A., Guo, F., Chen, W., Ni Usadel, D.B., Fernie, A.R. and Wen, W. (2020) Genome Assembly of Wild Tea Tree DASZ Reveals Pedigree and Selection History of Tea Varieties. Nature Communications, 11, 3719. https://doi.org/10.1038/s41467-020-17498-6

[49] Brophy, J.J., Craven, L.A. and Doran, J.C. (2013) Melaleucas: Their Botany, Essential Oils and Uses. Australian Centre for International Agricultural Research, Canberra, 73 .

[50] Hammer, K., Carson, C., Riley, T. and Nielsen, J. (2006) A Review of the Toxicity of Melaleuca alternifolia (Tea Tree) Oil. Food and Chemical Toxicology, 44, 616-625. https://doi.org/10.1016/j.fct.2005.09.001

[51] Cao, H., Yang, G., Wang, Y., Liu, J.P., Smith, C.A., Luo, H. and Liu, Y. (2015) Complementary Therapies for Acne Vulgaris. Cochrane Database of Systematic Reviews (Systematic Review), 1, CD009436. https://doi.org/10.1002/14651858.CD009436.pub2

[52] Chen, Z. M. and Chen, L. (2012) Delicious and Healthy Tea: An Overview. In: Chen, L., Apostolides, Z. and Chen, Z.M., Eds., Global Tea Breeding. Achievements Challengers and Prospective, Zhejiang University Press, Hangzhou, Berlin, Heidelberg, Springer-Verlag, 1-11.

[53] Hart, P.H., Brand, C., Carson, C.F., Riley, T.V., Prager, R.H. and Finlay-Jones, J.J. (2000) Terpinen-4-ol, the Main Component of the Essential Oil of Melaleuca alternifolia (Tea Tree Oil), Suppresses Inflammatory Mediator Production by Activated Human Monocytes. Inflammation Research, 49, 619-626.

https://doi.org/10.1007/s000110050639

[54] Moreira, M., Ponce, A., Del Valle, C. and Roura, S. (2005) Inhibitory Parameters of Essential Oils to Reduce a Foodborne Pathogen. LWT-Food Science and Technolo- 
$g y$, 38, 565-570. https://doi.org/10.1016/j.lwt.2004.07.012

[55] Carson, R.F. and Rilley, T.V. (2008) Toxicity of the Essential Oil of Melaleuca alternifolia. Journal of Clinical Toxicology, 33, 193-234.

https://doi.org/10.3109/15563659509000474

[56] Budhiraja, S.S., Cullum, M.E., Sioutis, S.S., Evangelista, L. and Habanova, S.T. (1999) Biological Activity of Melaleuca alternifola (Tea Tree) Oil Component, Terpinen-4-ol, in Human Myelocytic Cell Line HL-60. Journal of Manipulative and Physiological Therapeutics, 22, 447-453.

https://doi.org/10.1016/S0161-4754(99)70033-3 